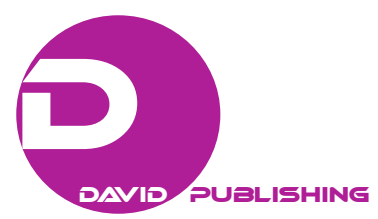

\title{
Social Media as a Learning Management System: Is it a Tool for Achieving the Goal of “Education for All”?
}

\author{
Wilson O. Otchie, Margus Pedaste \\ University of Tartu, Tartu, Estonia
}

\begin{abstract}
Social media (SM) Apps, such as Facebook, Twitter, YouTube, Instagram, etc. are very interactive and empower people to socialize, interact, communicate, and share information from anywhere and at any time without face-to-face (F2F) contact. However, the usability and functionality of SM make it easily accessible and affordable. Thus, it is a potential educational resource for achieving the right to education for all (EFA), as cited in Article 26 of the Charter of the United Nations (UN). Ultimately, SM empowers people to easily obtain access to information and educational resources. This paper reviews the highlights of SM appropriation in the context of learning, explores using SM as a learning management system (LMS), and provides learning scenarios for implementing SM as an LMS in the teaching and learning of science. Findings from the study suggest that using SM as an LMS could help maximize its potential and make teaching and learning more effective and interesting.
\end{abstract}

Keywords: social media, learning management system, formal learning, informal learning

\section{Introduction}

Education is the key to every human development and many nations are economically successful largely because of their investments in education. Since 1945, the United Nations (UN) has acknowledged and declared in Article 26 of its Charter that "everybody has the right to education" (Schutter, 2010). However, despite the declaration and the many social interventions that the UN introduces, including the Education for All (EFA) initiative, the Millennium Development Goals (MDGs 1 \& 2) from 2000, and the Sustainable Development Goal (SDG) from 2012, many children who are required to be in school are not in school, because their parents cannot afford the cost of education. Many of those who can afford an education are likewise denied their right due to the problem of accessibility (Global Campaign for Education, n.d.). Ultimately, the UN's interventions have achieved some successes in terms of an EFA (Max \& Esteban, 2018). Nonetheless, a lot more needs to be done to make education more accessible and highly affordable to all, without limitations to race, creed, nationality, and social status.

Essentially, the turn of the 21st century has brought in its wake the digital revolution, thereby constantly evolving and potentially breaking the frontiers of human capabilities and limitations from Web 1.0 applications to those of Web 2.0, etc. Interestingly, however, one significant development that has emerged with this digital revolution is the fact that globalization is presently more of a reality than a concept, i.e., one can easily access information from any part of the globe by just the press of a button.

Wilson O. Otchie, Ph.D. student (M.Phil.), Institute of Education, University of Tartu.

Margus Pedaste, Ph.D., professor, Institute of Education, University of Tartu. 
It is worth acknowledging that social media (SM) and Web 2.0 have brought the world and humanity closer together than one could have ever imagined. SM, which is powered by Web 2.0 applications, is a virtual platform that is very interactive and empowers people to socialize, interact, communicate, and share information without face-to-face (F2F) contact (Bidwell et al., 2014). Facebook, Twitter, Instagram, YouTube, WhatsApp, Google ${ }^{+}$, Flickr, and LinkedIn are but only a few of the SM Apps in use today (Calvert, 2015), and the trend in terms of global usage makes SM a potentially ubiquitous toolkit for many (Kaplan \& Haenlein, 2010; Lindsay, 2011; Wang, Chen, \& Liang, 2011). However, the usability and functionality of SM have potential regarding the realization of the right to EFA, as cited in the 1945 Charter of the UN.

\section{Benefits of Social Media}

Globally, SM use has gained such phenomenal popularity in the media landscape in recent years, because it is interactive and facilitates online discussions and information dissemination (Greenhow, 2016). Again, because it is largely accessible, a person only needs a smartphone and Internet connectivity to log into any SM platform. Furthermore, its relative affordability also makes it possible for many people to download and use SM.

A study carried out by Gülbahar, Kalelioğlu, and Madran (2010, as cited in Kalelioğlu, 2017), summed up by using SM (Facebook, YouTube, Twitter, etc.) in the context of educational perspectives. Ultimately, the authors identified Facebook and Twitter as being useful for sharing materials (such as video clips, photographs, audio files, presentations, text files, Websites, etc.), following daily news or group discussions, and facilitating collaborative learning and critical thinking skills development. Gülbahar and Kalelioğlu (2010) went even further and established the fact that Flikr can also be effectively used in educational contexts for visual presentations, video collections, and brainstorming discussions and to prepare e-portfolios for learning and assessment. These functionalities and affordances in SM make it a potential educational tool that could be used as a learning management system (LMS) in teaching and learning in the high school curriculum. In a systematic literature review, Otchie and Pedaste (n.d.) identified the following seven categories of approaches for using SM in learning: (a) interaction, (b) information dissemination, (c) communication, (d) collaboration, (e) teaching, learning, and resource sharing, (f) socialization, and (g) entertainment.

Many studies conducted in the recent past have demonstrated the use of digital technology as an LMS through various theoretical perspectives. For instance, studies by Leow and Neo (2013; 2014) use the communication model of collaborative learning (CMCL) and Jonassen's model for designing constructivist learning environments (CLE) as an LMS on a Web 2.0 platform. In a similar study, Kalelioğlu (2017) focused on using Facebook as an LMS. These studies put into perspectives how SM could be used in the context of learning as an LMS.

According to Leow and Neo (2013), Web-based tools, such as SM and constructivist-based environments enable students to be more engaged in the construction of knowledge through collective interactive activities, which makes learning more real and meaningful, thus creating a bond among the students (Jonassen, 1998; Jonassen, Davidson, Collins, Campbell, \& Haag, 1995; Suh, 2011).

According to Greenhow, Robelia, and Hughes (2009), a stronger focus on students' everyday use of Web 2.0 platforms in the context of learning both in and out of classroom environments would largely benefit the stakeholders in education. 


\begin{abstract}
Abuse of Social Media
In contrast, however, some researchers are of the view that only a small percentage of students use SM in an educational context (formal learning [FL]) that might benefit educators (Eynon \& Malberg, 2011; Ito et al., 2008). Additionally, many students are carried away by the term "social” in that they use SM largely for social-oriented activities, thus making friends, chatting online, watching trending movies, and other social-oriented activities as opposed to learning (Selwyn, 2009). According to Andersson, Hatakka, Grönlund, and Wiklund (2014), SM is distractive to students' learning, which negatively affects their grades (Kirschner \& Karpinski, 2010).

Similarly, Ndaku (2013) observed that students spend too much time on SM, which affects their study time. Moreover, some related studies have also found problems that students encounter due to SM abuse, including addiction, peer-pressure (Andreassen, 2015), and different emotional problems, such as depression and anxiety (Elhai, Levine, Dvorak \& Hall, 2016; Elhai, Dvorak, Levine, \& Hall, 2017), social phobia (Enez Darcin et al., 2016), and aggressive behaviour (Lee et al., 2016).

Using SM for social-oriented activities could be seen in the context of informal learning (IL). However, there is a need to determine how the two approaches of learning with SM (i.e., formal and informal learning) could be connected and managed to potentially enhance the total learning capacity of the student.

According to Greenhow (2016), the debate continues regarding the benefits and challenges of using SM in the context of learning, yet little attention is given to the assessment of the potential benefit that could be derived from the linking of SM to formal and informal learning. However, regardless of the varied arguments and perspectives of educators on SM, its potential to be used as an LMS cannot be underestimated.

The purpose of this paper is to explore SM in the context of a LMS. This purpose was identified, because there are no concrete scenarios that could be used for applying SM effectively in education, as was identified in our previous systematic review, in which we provided a solution with a theoretical rationale (Otchie \& Pedaste, n.d.).
\end{abstract}

The methodology we adopted for this study was to review the literature on the potential affordances of using SM as a LMS. The paper specifically addresses the following three fundamental issues:

1. highlight the potential learning affordances in SM;

2. discuss using SM as a LMS;

3. implement both 1 and 2 in providing learning scenarios for using SM as an LMS in learning science.

\title{
Social Media in Learning
}

The focus herein is to delve more into the context of formal learning with SM. However, the narrative will expand to cover learning in the informal context as well. Incidentally, this approach will give us an overview of the connection between formal and informal learning, as well as the potential benefits that using SM for formal learning can derive from this relationship.

According to Obar and Wildman (2015), SM is a Web 2.0-based computer-mediated application that has user-generated content, including a user-specific profile. SM is an interactive digital platform that facilitates online chats, collaboration, communication, group discussions, information dissemination, and resource sharing (Greenhow \& Lewin, 2016; Mao, 2014). Some of the most popular and frequently used SM Apps include Facebook, YouTube, Instagram, Twitter, WhatsApp, and blogs. Computers, laptops, and smartphones are 
electronic devices on which one can connect to the internet to access SM Apps. Smartphones, among the other tools, as their name implies, are small, affordable, handy, and relatively fast electronic devices that most people find highly convenient and prefer to access their Internet services. However, Pedaste et al. (2017) have shown that most students might have smartphones for the ubiquitous use of SM in learning, but most of them rarely do so. In their study of the Estonian context, only approximately 5\% of students use smartphones almost every day in learning science and math, not only using diverse approaches, such as collecting and sharing information, but also collaborating with others and creating digital content.

Many studies suggest that student-centred learning is more effective, because it is more interactive and collaborative and motivates the learner more so than the teacher-centred approach (Greenhow \& Lewin, 2016; Leow \& Neo, 2013; Jonassen et al., 1995; Jonassen, 1998; Suh, 2011). According to Vygotsky (1978), learning becomes more effective through modelling and activity-based teaching, and therefore, entreats teachers to adopt more interactive teaching methods. The constructivist perspective is also emphasized by Mayer (2005) in his cognitive theory of multimedia learning (CTML). According to CTML, learning becomes more effective when pictures are combined with words than it is with words only. This finding adds to the opinions of many scholars that SM is a potential LMS, because it is more interactive and can also be used for communication, collaboration, and identity work, or it can have a positive cognitive emotional impact (Gao, Luo, \& Zhang, 2012; Greenhow \& Robelia, 2009a, 2009b; Ranieri, Manca, \& Fini, 2012).

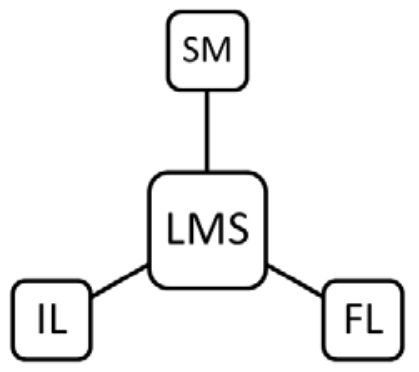

Figure 1. The connection between formal and informal learning with SM as an LMS.

However, based on the concept and clarification of learning, it is therefore indicative that learning actually takes place whenever SM is used. Obviously, the basis of appropriating SM in the context of learning is to obtain high grades in school that have direct links to the acquiring of knowledge and skills through FL. Likewise, IL occurs during the process when one learns the skills of using a digital device (e.g., smartphone), as well as using SM Apps for social-oriented activities. This aspect of learning (i.e., IL) is not remote. Instead, it has a direct link to a person's knowledge, skill, and competence to effectively use SM for academic activity. The current study conceptualizes this relationship in terms of formal and informal learning with SM as an LMS (see Figure 1). Essentially, the model synthesizes a direct link between IL and FL with SM as an LMS. Consequently, the students' knowledge that is acquired through IL with SM (e.g., the ability to use a smartphone, chat online, connect to friends, etc. on an SM App) provides them with the skills and competencies to use digital devices (e.g., tablets, smartphones, etc.), to use SM Apps (e.g., Facebook, YouTube, etc.) and to develop the skills needed to easily and confidently navigate the SM environment. Essentially, IL with SM has more or less already addressed that aspect of the teacher's task of teaching students how to operate digital devices and how to use SM Apps. It is therefore instructive that this knowledge and these skills already 
acquired by the students facilitate the integration of SM as an LMS in the context of FL. Eventually, the teacher's only task is how to engage the students to apply their informal knowledge and skills from SM into FL. However, in conceptualizing IL and SM into an LMS framework, it is imperative to acknowledge and appreciate its significance. Thus, IL provides both teachers and students with the essential skills and knowledge for using SM as an LMS.

\section{Social Media as a Learning Management System}

Many studies have identified SM as a potential tool for teaching and learning (Greenhow \& Lewin, 2016; Jones, 2015; Kalelioğlu, 2017; Manca \& Ranieri, 2016; Pearce \& Learmonth, 2013). However, to maximize the benefits of learning with SM, it is important to manage that learning through a system. The LMS is a tool used by many organizations and academic institutions to train and manage their resources. SM on the LMS platform could be used to manage the different subjects studied in high schools due to its three main characteristic features (Coates, James, \& Baldwin, 2005; Meishar-Tal, Kurtz, \& Pieterse, 2012; Morgan, 2003) as follows:

1. It allows for the creation and delivery of different contents, such as lecture notes, presentation slides, videos, articles, links, etc.;

2. It facilitates synchronous and asynchronous communication and collaboration through discussion forums, chats, blogs, and conference tools;

3. It provides administrative and assessment tools for recording tasks, grading, and soliciting feedback.

However, it is instructive that most of the characteristic features listed for an LMS are almost similar to those of SM applications (e.g., Facebook, YouTube, Twitter, WhatsApp, etc.), except for the administrative and assessment tools. Apparently, the assessment feature could be addressed with Apps, such as Kahoot!, which is basically for assessment. This result could be achieved by sharing links from Kahoot! with a class SM page.

Basically, Facebook, like most SM Apps, could be used for group discussions (Kurtz, 2014) and students' peer-to-peer learning (Dalsgaard, 2014). For instance, in using SM as an LMS, the following six-step framework must be observed:

1. The teacher creates a "closed" SM group account of the class comprising only the teacher and his students;

2. The teacher becomes the administrator of the platform and therefore coordinates activities and protocols on the page;

3. The teacher updates the SM group page daily with video links, academic documents, assignments, and presentations;

4. The students discuss the academic content, present their opinions, and sometimes ask the teacher for help;

5. Class assessment exercises involve questions from the videos, blogs, presentations, etc. from the class SM group platform;

6. The teacher gives feedback on the class SM group page.

\section{Scenarios for Learning Science With Social Media as an LMS}

In several studies, teachers have positive attitudes and impressions about using technology in the classroom (O’Bannon, Waters, Lubke, Cady, \& Rearden, 2017; Pynoo, Devolder, Tondeur, van Braak, W. Duyck, \& P. Duyck, 2011). However, the following part of the narrative will explore some scenarios for 
implementing SM as an LMS for science lessons. We will provide an example scenario for an 8th grade biology class.

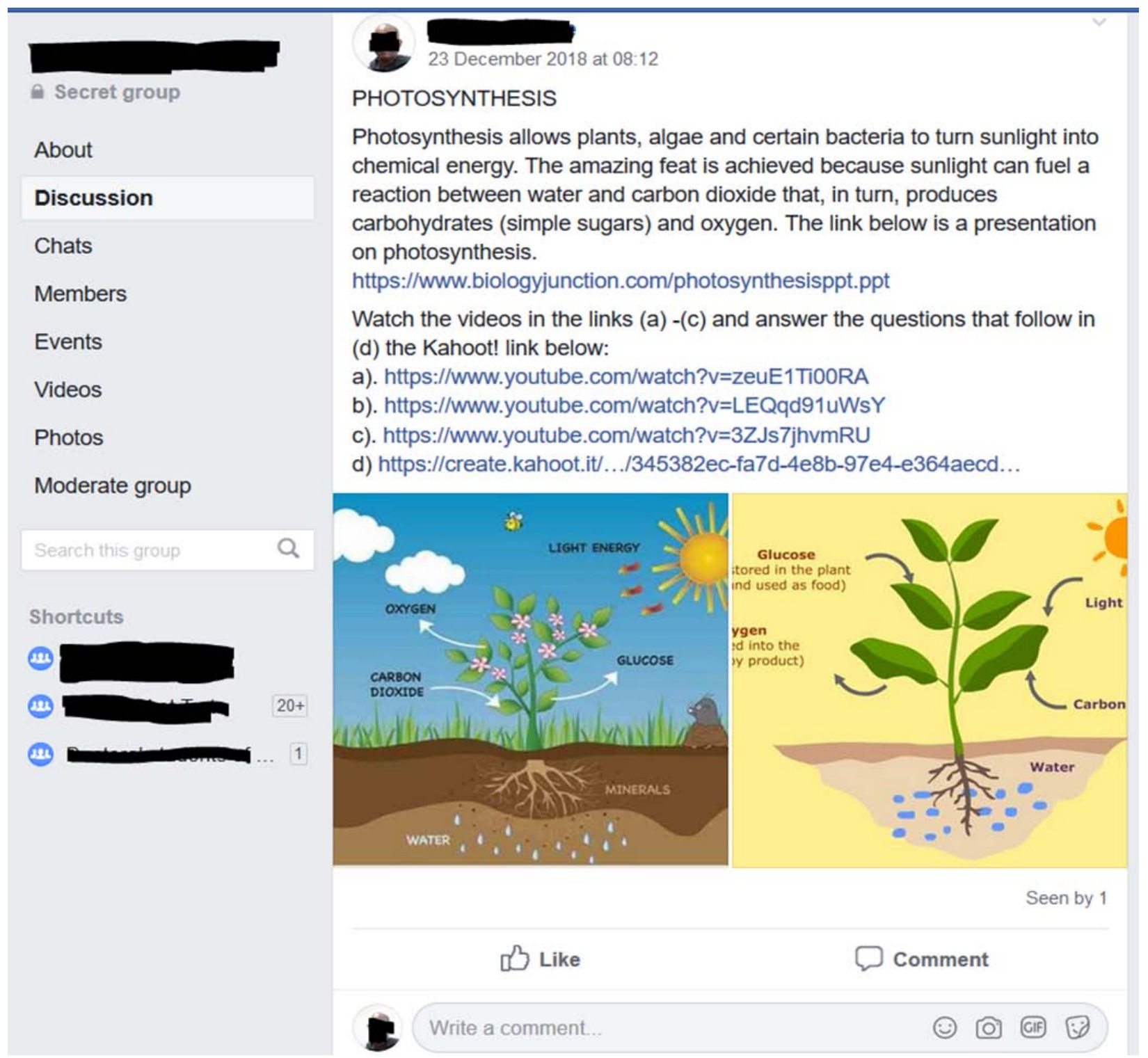

Figure 2. Screenshot of a Facebook account of a class with biology lesson materials.

First, to implement SM as an LMS in an 8th grade biology class, it is important to conduct a pre-test assessment in which students fill out questionnaires to evaluate their skills and appreciation of using technology in learning. In a related study, Adov, Must, and Pedaste (2017) found that schools are sometimes unable to provide all of their students with mobile devices. Hence, working in pairs or groups becomes the only choice, especially when learning with mobile devices. Nonetheless, this approach comes with some advantages, i.e., the more experienced students could support their peers (Pedaste et al., 2017). However, because mobile devices are key to using technology in learning, it is instructive for our study to review collaborative learning with these devices. It is also important to conduct a post-test assessment to evaluate the students' impressions or sentiments after their encounter with the technology. Additionally, a second post-test assessment will be 
conducted to obtain opinions from the science teachers and parents of the participating class. This assessment could be viewed through the lenses of the unified theory of acceptance and use of technology (UTAUT) and the technology acceptance model (TAM), whereby enjoyment (attitude), effort expectancy (ease of use), performance expectancy (usefulness of technology), social influence, and facilitating conditions are seen to be critical elements in the acceptance and use of technology (Davis, 1989; Venkatesh, Morris, G. Davis, \& F. Davis, 2003).

Second, we consider the following scenarios in teaching and learning with SM as an LMS (see Figure 2):

1. Upload the class SM platform with curriculum content (e.g., biology lesson materials), which may include the following:

(a) Notes with graphic illustrations of the biology lesson in the form of texts or slides;

(b) Video clips on the topic from links, e.g., YouTube or Vimeo;

(c) Assessment questions and instructions.

The platform also has a number of tools for chats, video, and audio calls. These tools will enable students to be motivated to effectively execute the assigned task. This could be done through online group discussions and collaborations either in class or at home. For example:

Topic: Photosynthesis

i. Objectives: By the end of the lesson, the student should be able to do the following:

(a) Describe the process of photosynthesis;

(b) List the factors responsible for photosynthesis;

(c) Explain the chemical reaction of photosynthesis.

ii. Activity: Experiment to test for starch:

(a) Materials/Apparatus

1. Bunsen burner, tripod stand, wire gauze (OR $90^{\circ} \mathrm{C}$ electric water bath OR hot plate);

2. 250- $\mathrm{cm}^{3}$ beaker;

3. Boiling tube;

4. A pair of forceps;

5. Test tube and test tube holder;

6. White tile;

7. A green leaf to be tested (e.g., a hibiscus leaf);

8. $90 \%$ ethanol;

9. Iodine/potassium iodide solution;

10. Dropping pipette.

(b) Method

1. Remove a green leaf from a plant that has been exposed to sunlight for a few hours;

2. Use the forceps to place the leaf in boiling water for two minutes (this kills the cells in the leaf to stop photosynthesis);

3. Put the leaf in the ethanol and heat it in boiling water for 10 minutes (this removes the green pigment in the leaf);

4. Wash the leaf in cold water and spread it on a white tile;

5. Add drops of iodine solution with a dropping pipette and note any observations.

iii. Assessment: Class Exercise 1 
Answer the questions below (30 minutes):

1. (a) Briefly explain the term photosynthesis; (2 points)

(b) Describe how the process of photosynthesis occurs; (3 points)

(c) Mention and explain the factors responsible for photosynthesis. (5 points)

2. Give four reasons why photosynthesis is very important to living things. (4 points)

3. (a) Write a balanced equation for photosynthesis; (2 points)

(b) What is the product of photosynthesis and why is it important? (4 points)

2. Allow students to work in groups of 2-3, with at least one member of each group having more experience with using mobile devices and SM Apps. This approach will make students' access to mobile devices easier and provide some benefits in terms of collaborative learning. Thus, the more experienced students could support their peers (Pedaste et al., 2017). Because the lesson involves an experiment on photosynthesis, it becomes necessary and convenient for the teacher to share a video link of the experiment from other SM Apps.

3. Assessment: upload questions from text files or links, such as Kahoot!, e.g., multiple choice, short answer, or essay.

4. Feedback is either F2F during the class lesson or online in SM.

5. Repeat scenario 1 for the homework.

6. The teacher initiates platform discussions on the homework in SM.

7. Submission of the homework through SM.

8. Feedback on the homework either in class or online in SM.

\section{Discussion}

It is indeed instructive and noteworthy that SM and Web 2.0 have truly brought the world and humanity closer than one could have ever imagined, thus making it possible for people to socialize, interact, communicate, and share information without F2F contact (Bidwell et al., 2014). However, this usability and functionality make SM a potential pedagogical tool to enable people to access education without limitations on time and space. Essentially, this development is a huge leap in addressing the problems of education in terms of affordability and accessibility, thus potentially achieving the goal of unlimited access to education.

For the study, we reviewed the highlights of appropriating SM in the context of learning, explored using SM as an LMS, and provided a learning scenario for the implementation of SM as an LMS in teaching science. Findings from the study suggest that using SM as an LMS could help maximize its potential and make teaching and learning more effective and interesting. In terms of learning, we established the connection between formal and informal learning with SM as an LMS. Herein, we proposed a six-step framework that teachers and students can follow to make maximum use of SM as an LMS in the teaching and learning process.

The approach is valuable in practice for several reasons. First, the popularity of SM lies in its interactivity and ease of use, both of which obviously empower people to communicate, share information and resources, have group discussions, and make friends online (Greenhow \& Lewin, 2016; Mao, 2014). The fact that SM is both interactive and collaborative also makes it a potential pedagogical tool for student-centred learning. Many studies suggest that student-centred learning is more effective, because it is more interactive and collaborative and motivates the learner more so than the teacher-centred approach (Greenhow \& Lewin, 2016; Leow \& Neo, 2013; Jonassen et al., 1995; Jonassen, 1998; Suh, 2011). Again, SM facilitates communication and information 
dissemination, which is vital to both teaching and learning. Moreover, distance learning today has become more popular and effective due to the evolution of Web 2.0 and SM, thus making it possible for many students from remote corners of the globe to access distance education. Additionally, a few institutions and students have Facebook accounts from which some lecturers and teachers send assignments and course materials to students. Similarly, some students use SM Apps, such as Facebook, Twitter, WhatsApp, etc., for group discussions, information dissemination, and the sharing of resources.

Second, to maximize using SM as a pedagogical tool, it is important to manage the process through an LMS. This is because an LMS is an effective resource that many organizations and academic institutions use to train and manage their resources. An LMS allows for the creation and delivery of different content, such as lecture notes, presentation slides, videos, articles, links, etc. It also facilitates synchronous and asynchronous communication and collaboration through discussion forums, chats, blogs, and conference tools. Furthermore, it provides administrative and assessment tools for recording tasks, grading, and soliciting feedback. These features of an LMS (apart from the administrative and assessment tools) are also present on SM Apps (e.g., Facebook, Twitter, YouTube, WhatsApp, etc.). This similarity gives SM the leverage necessary to be used as an LMS in the teaching and learning of different subjects in high schools. However, it is necessary to have a framework to make SM relatively more structured and less complex for teachers and students to use. Therefore, we proposed a six-step framework, which teachers and students can follow to enable them to effectively maximize using SM as an LMS.

Finally, a pre-test and post-test will help teachers evaluate the extent of the impact of the intervention on their students. This assessment will obviously give them the opportunity to make an informed and more conclusive deduction from any study that uses SM as an LMS.

\section{Conclusion}

The purpose of the study was to explore using SM in the context of an LMS. Generally, the narrative took an overview of education from the global perspective of the UN's EFA policy. It has, however, been established that SM could play a critical role in addressing global problems related to making education more affordable and accessible. Consequently, however, such affordability and accessibility have been goals of the UN since 1945. The UN has subsequently outlined certain social interventions to make education more accessible and affordable. The current study has found that SM has the potential to become a learning resource. To maximize its potential and minimize any potential risks, this study attempts to structure SM as an LMS, because it shares many commonalities with LMS in terms of features. This structure will ensure that teachers have a framework to use for teaching with SM. Again, students in remote parts of the world will only need a smartphone and Internet connectivity to access their lessons from school. This access could help make the goal of education, as cited in the Charter of the UN, become a reality. Nevertheless, it is also important for stakeholders to create an enabling environment wherein both teachers and students are motivated to study SM platforms beyond the boundaries of the school. Finally, it is believed that the adoption and integration of SM as an LMS could eliminate the invisible barriers that separate school from home, so that students could learn anytime and anywhere, which would ultimately positively impact both teaching and learning. 


\section{References}

Adov, L., Black, O., \& Pedaste, M. (2017). Attitudes towards mobile devices in estonian basic education: Using the framework of the UTAUT model (pp. 319-329). Springer: Cham. Retrieved from https://doi.org/10.1007/978-3-319-58515-4_25

Andersson, A., Hatakka, M., Grönlund, A., \& Wiklund, M. (2014). Reclaiming the students—Coping with social media in 1:1 schools. Learning, Media and Technology, 39(1), 37-52.

Andreassen, C. S. (2015). Online social network site addiction. A Comprehensive Review, 2(2), $175-184$. https://doi.org/10.1007/s40429-015-0056-9

Bidwell, N. J., Robinson, S., Vartiainen, E., Jones, M., Siya, M. J., Reitmaier, T., ..., \& Lalmas, M. (2014). Designing social media for community information sharing in rural South Africa. Retrieved November 10, 2018, from https://cronfa.swan.ac.uk/record/cronfa18726/details

Biermann, F., Stevens, C., Bernstein, S., Gupta, A., Kabiri, N., Kanie, N., ..., \& Young, O. R. (2014). Integrating governance into the sustainable development goals: Policy brief. Retrieved November 10, 2018, from http://collections.unu.edu/eserv/unu:1825/post2015_unu-ias_policybrief3.pdf

Calvert, S. L. (2015). Children and digital media. Retrieved November 10, 2018, from http://cdmc.georgetown.edu/wp-content/uploads/2015/03/10-calvert-hocpads-7e-v4-c10_final_2015.pdf

Coates, H., James, R., \& Baldwin, G. (2005). A critical examination of the effects of learning management systems on university teaching and learning. Tertiary Education and Management, 11, 19-36.

Dalsgaard, C. (2014). Students' use of Facebook for peer-to-peer learning. In S., Bayne, C., Jones, M., de Laat, T., Ryberg, and C. Sinclair (Eds.), 9th International Conference on Networked Learning 2014 (pp. 95-102), Edinburgh, Scotland.

Davis F. D. (1989). Perceived usefulness, perceived ease of use, and user acceptance of information technology. MIS Quartely, 13, 319-339.

Elhai, J. D., Levine, J. C., Dvorak, R. D., \& Hall, B. J. (2016). Fear of missing out, need for touch, anxiety and depression are related to problematic smartphone use. Computers in Human Behavior, 63, 509-516. https://doi.org/10.1016/j.chb.2016.05.079.

Elhai, J. D., Dvorak, R. D., Levine, J. C., \& Hall, B. J. (2017). Problematic smartphone use: A conceptual overview and systematic review of relations with anxiety and depression psychopathology. Journal of Affective Disorders, 207, 251-259. https://doi.org/10.1016/j.jad.2016.08.030.

Encyclopædia Britannica. (2017). Learning. Encyclopædia Britannica, Inc. https://www.britannica.com/science/learning

Enez Darcin, A., Kose, S., Noyan, C. O., Nurmedov, S., Y1lmaz, O., \& Dilbaz, N. (2016). Smartphone addiction and its relationship with social anxiety and loneliness. Behaviour and Information Technology, 35(7), 520-525. https://doi.org/10.1080/0144929x.2016.1158319

Eynon, R., \& Malmberg, L. (2011). A typology of young people’s Internet use: Implications for education. Computers and Education, 56(3), 585-595.

Gao, F., Luo, T., \& Zhang, K. (2012). Tweeting for learning: A critical analysis of research on microblogging in education published in 2008-2011. British Journal of Educational Technology, 43(5), 783-801.

Global Campaign for Education. (n.d.). Retrieved November 10, 2018, from http://www.campaignforeducation.org/

Greenhow, C., \& Robelia, E. (2009). Old communication, new literacies: Social network sites as social learning resources. Journal of Computer-Mediated Communication, 14, 1130-1161.

Greenhow, C., \& Robelia, E. (2009). Informal learning and identity formation in online social networks. Learning, Media and Technology, 34(2), 119-140.

Greenhow, C., \& Robelia, E. (2016). Social media and education: Reconceptualizing the boundaries of formal and informal learning. Learning, Media and Technology, 41(1), 6-30.

Greenhow, C., Robelia, E., \& Hughes, J. (2009). Web 2.0 and classroom research: What path should we take now? Educational Researcher, 38(4), 246-259.

Gülbahar, Y., \& Kalelioğlu, F. (2010, April 26-28). Use of Flickr for language teaching. In 10th International Educational Technology Conference, Boğaziçi University, İstanbul, Turkey.

Ito, M., Horst, H., Bittanti, M., Boyd, D., Herr-Stephenson, B., Lange, P. G., .., \& Trippet, L. (2008). Living and learning with new media: Summary of findings from the Digital Youth Project. In The John D. and Catherine T. MacArthur Foundation Reports on Digital Media and Learning. Retrieved January 30, 2009, from http://digitalyouth.ischool.berkeley.edu/report 
Jonassen, D. (1998). Designing constructivist learning environments. In C. M. Reigeluth (Ed.), Instructional design theories and models: A new paradigm of instructional theory (pp. 215-239). Hillsdale, N.J.: Lawrence Erlbaum Associates.

Jonassen, D., Davidson, M., Collins, M., Campbell, J., \& Haag, B. (1995). Constructivism and computer mediated communication in distance education. American Journal of Distance Education, 9(2), 7-25.

Jones, A. (2015). Social media for informal minority language learning: Exploring Welsh learners' practices. Journal of Interactive Media in Education, 7(1), 1-9. doi: http://dx.doi.org/10.5334/jime.ak

Kalelioğlu, F. (2017). Using Facebook as a learning management system: Experiences of pre-service teachers. Informatics in Education, 16(1).

Kaplan, A. M., \& Haenlein, M. (2010). Users of the world, unite! The challenges and ... Business Horizons, 53(1). Retrieved November 10, 2018, from https://sciencedirect.com/science/article/pii/s0007681309001232

Kirschner, P. A., \& Karpinski, A. C. (2010). Facebook ${ }^{\circledR}$ and academic performance. Computers in Human Behavior, 26(6), 1237-1245. https://doi.org/10.1016/j.chb.2010.03.024

Kurtz, G. (2014). Integrating a Facebook group and a course website: The effect on participation and perceptions on learning. American Journal of Distance Education, 28(4), 253-263.

Leow, F. T., \& Neo, M. (2013). Assessing collaboration in a web-based constructivist learning environment: A Malaysian perspective. In H. Carter, M. Gosper, and J. Hedberg (Eds.), Electric dreams: Proceedings ascilite 2013 (pp. 503-513). Sydney.

Leow, F. T., \& Neo, M. (2014). Interactive multimedia learning: Innovating classroom education in a Malaysian university. Turkish Online Journal of Educational Technology, 13(2), 99-110.

Lee, J., Sung, M. J., Song, S. H., Lee, Y. M., Lee, J. J., Cho, S. M., ..., \& Shin, Y. M. (2016). Psychological factors associated with smartphone addiction in South Korean adolescents. The Journal of Early Adolescence. doi: https://doi.org/10.1177/0272431616670751

Lindsay, B. R. (2011). Social media and disasters: Current uses, future options, and policy considerations. Retrieved November 10, 2018, from https://fas.org/sgp/crs/homesec/r41987.pdf

Manca, S.. \& Ranieri, M. (2016). Facebook and the others: Potentials and obstacles of social media for teaching in higher education. Computers and Education, 95, 216-230.

Mao, J. (2014). Social media for learning: A mixed methods study of high school students' technology affordances and perspectives. Computers in Human Behavior, 33, 213-223.

Max, R., \& Esteban, O. O. (2018). Primary and secondary education. Published online at OurWorldInData.org. Retrieved from https://ourworldindata.org/primary-and-secondary-education

Mayer, R. E. (2005). Cognitive theory of multimedia learning. In R. E. Mayer (Ed.), The Cambridge handbook of multimedia learning (pp. 31-48). New York, NY: Cambridge University Press.

Meishar-Tal, H., Kurtz, G., \& Pieterse, E. (2012). Facebook groups as LMS: A case study. The International Review of Research in Open and Distance Learning, 13(4). Retrieved from http://www.irrodl.org/index.php/irrodl/article/view/1294/2295

Morgan, G. (2003). Faculty use of course management systems. Boulder, CO: EDUCAUSE Center for Applied Research. Retrieved from https://net.educause.edu/ir/library/pdf/ers0302/rs/ers0302w.pdf

National Board for Technical Education (NBTE). (n.d.). Retrieved November 10, 2018, from http://www.nbte.gov.ng/

Ndaku, A. J. (2013). Impact of social media on the students' academic performance in Ghana. Networking, 18(5), $275-285$.

Obar, J. A., \& Wildman, S. (2015). Social media definition and the governance challenge: An introduction to the special issue. Telecommunications Policy, 39(9), 745-750. https://doi.org/10.1016/j.telpol.2015.07.014

O’Bannon, B. W., Waters, S., Lubke, J., Cady, J., \& Rearden, K. (2017). Teachers and students poised to use mobile phones in the classroom. Computers in the Schools, 34(3), 125-141. doi: 10.1080/07380569.2017.1347454

Otchie, W. O., \& Pedaste, M. (n.d.). Using social media for learning: A systematic literature review (Unpublished).

Pearce, N., \& Learmonth, S. (2013). Learning beyond the classroom: Evaluating the use of interest in learning and teaching in an introductory anthropology class. Journal of Interactive Media in Education, 2(1),12. doi: http://doi.org/10.5334/2013-12

Pedaste, M., Must, O., Leijen, Ä., Mäeots, M., Siiman, L., Kori, K., \& Adov, L. (2017). Nutiseadmete kasutamise profiilid loodusainete ja matemaatika õppimise kontekstis: Eesti Haridusteaduste Ajakiri (Profiles of students who use mobile devices for the purposes of learning science and mathematics). Estonian Journal of Education, 5(1), 99-129. doi: https://doi.org/10.12697/eha.2017.5.1.04

Pynoo, B., Devolder, P., Tondeur, J., van Braak, J., Duyck, W., \& Duyck, P. (2011). Predicting secondary school teachers' acceptance and use of adigital learning environment: A cross-sectional study. Computers in Human Behavior, 27(1), 568-575. 
Renieri, M., Manca, S., \& Fini, A. (2012). Why (and how) do teachers engage in social networks? An exploratory study of professional use of Facebook and its implications for lifelong learning. British Journal of Educational Technology, 43(5), 754-769.

Schutter, O. D. (2010). International human rights law: The United Nations Charter-based monitoring of human rights. Retrieved November 10, 2018, from http://ebooks.cambridge.org/chapter.jsf?bid=cbo9780511779312\&cid=cbo9780511779312a064

Selwyn, N. (2009). Faceworking: Exploring students' education-related use of Facebook. Learning, Media andTechnology, 34(2), 157-174.

Sustainable Development Goals ... Sustainable Development ... (n.d.). Retrieved November 10, 2018, from http://sustainabledevelopment.un.org/?menu=1300

Suh, H. (2011). Collaborative learning models and support technologies in the future classroom. International Journal for Educational Media and Technology, 5(1), 50-61.

Venkatesh, V., Morris, M. G., Davis, G. B., \& Davis, F. D. (2003). User acceptance of information technology: Toward a unified view. Mis Quarterly, 27(3), 425-478.

Vygotsky, L. (1978). Mind in society. Cambridge, MA: Harvard University Press.

Wang, Q., Chen, W., \& Liang, Y. (2011). The effects of social media on college students. Retrieved November 10, 2018, from https://scholarsarchive.jwu.edu/mba_student/5 